\title{
Age at menarche, eating disorders, and their relationships with some parameters in female adolescents in Iran
}

\author{
Lida Daeie-Farshbaf ${ }^{1}$, Mehrangiz Ebrahimi-Mameghani ${ }^{2}$, Parvin Sarbakhsh ${ }^{3}$, Neda Roshanravan ${ }^{4}$ \\ and Ali Tarighat-Esfanjani ${ }^{2^{*}}$ (D)
}

\begin{abstract}
Objective: Adolescence as one of the most challenging periods of humans' growth is accompanied with major physical, behavioural, social-emotional, and neuroendocrine changes. Early maturation and eating disorders (EDs) have been reported to be associated with adverse health conditions. Therefore, the present study was conducted to assess age of onset of menarche (AM), EDs, and their possible relationships with weight, body mass index (BMI), waist circumference (WC), and socioeconomic status (SES) in the Iranian female adolescents.

Results: In the study population, mean \pm standard deviation (SD) of AM was $12.95 \pm 1.14$ years. Inverse significant relationships were found between weight and $\mathrm{AM}$, also BMI and $\mathrm{AM}(p<0.05)$. There was a negative association between weight and anorexia nervosa (AN), BMI and AN, also WC and AN $(p<0.001)$. A significant positive correlation was found between SES and AM, also EDs and AM $(p<0.05)$ then between weight and bulimia nervosa $(B N)$ \& binge-eating disorder (BED), BMI and BN \& BED, also WC and BD \& BED $(p<0.001)$. Our results also revealed that AM in mothers had a significant positive relationship with AM in their daughters $(p<0.001, r=0.34)$.
\end{abstract}

Keywords: Adolescent, Anthropometry, Eating disorders, Girls, Menarche

\section{Introduction}

Menarche is often considered as a hallmark of puberty among females [1]. The age of menarche (AM) is of great importance in terms of clinical, public health, and social factors [2]. In the last two decades, a downward trend has been reported in the median age at menarche (14 years) in less-developed countries as well as some well-developed countries [3]. Early maturation has been found to be associated with adverse health conditions and development of a broad range of psychopathological symptoms like eating disorders (EDs) during adolescence [4-6].

\footnotetext{
*Correspondence: Tarighata@tbzmed.ac.ir

${ }^{2}$ Nutrition Research Center, School of Nutrition and Food Sciences,

Tabriz University of Medical Sciences, Attar Nishabouri St., POBOX: 14711

Tabriz 5166614711, Iran

Full list of author information is available at the end of the article
}

Overall, early maturation has greater effects for girls in comparison with boys as reported by a study that has demonstrated the elevated internalizing and externalizing symptoms during early and mid-adolescence along with the elevated risk for EDs in mid and late adolescence [7]. Also, early menarche could accelerate skeletal maturation leading to short height of the adults [8].

Strong evidence shows that the increased rate of obesity in children is a significant factor contributing to early onset of menarche [9]. Matkovic et al. [10] showed that gain in body fat of $1 \mathrm{~kg}$ results in a 13-day reduction in AM. The adolescents with EDs frequently have menstrual abnormalities reflecting their abnormal nutritional intake [11]. Amenorrhea occurs in $68 \%$ of the individuals associated with weight loss, rigorous sports-related activities, and extreme calorie restriction $[12,13]$. Although, several studies have found an association between age of pubertal

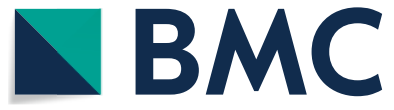

(c) The Author(s) 2021. This article is licensed under a Creative Commons Attribution 4.0 International License, which permits use, sharing, adaptation, distribution and reproduction in any medium or format, as long as you give appropriate credit to the original author(s) and the source, provide a link to the Creative Commons licence, and indicate if changes were made. The images or other third party material in this article are included in the article's Creative Commons licence, unless indicated otherwise in a credit line to the material. If material is not included in the article's Creative Commons licence and your intended use is not permitted by statutory regulation or exceeds the permitted use, you will need to obtain permission directly from the copyright holder. To view a copy of this licence, visit http://creativeco mmons.org/licenses/by/4.0/. The Creative Commons Public Domain Dedication waiver (http://creativecommons.org/publicdomain/ zero/1.0/) applies to the data made available in this article, unless otherwise stated in a credit line to the data. 
development and body mass index (BMI) [14-16], others have failed to find any association in this regard $[17,18]$. Studying menstrual disorders is an opportunity for early diagnosis and treatment of the people with EDs [11].

According to review of the literature, there was different and somewhat contradictory evidence regarding $\mathrm{AM}$ and EDs and their relationship with anthropometric parameters, and socioeconomic status (SES) so, herein, it was attempted to study AM and EDs and their relationship with weight, BMI, waist circumference (WC), and SES in the Iranian female adolescents.

\section{Main text Methods}

This cross-sectional study included female students aged 14-18 years that were selected randomly from public and private high schools in all five educational districts during academic year of 2015-2016 in Tabriz, Iran $(n=725)$. Students with any endocrine disorders, hormonal disorders, or delayed menarche were excluded from the study.

Purpose of the study and instructions for completing questionnaires were explained for the selected students in a training session. An informed written consent was obtained from all the participants and their guardian.

\section{Data collection}

All the participants were asked to complete a researchermade questionnaire containing demographic and SES characteristics. SES was assessed by collecting data regarding parents' educational and occupational situation, number of family members, and type of school, and was categorized into "low", "moderate", and "high" subgroups. An Eating Disorders Diagnostic Scale (EDDS) was used based on diagnostic and statistical manual of mental disorders, fourth edition (DSM-IV) for diagnosis of EDs [19]. Validity of this questionnaire has been previously tested by Khabir [20]. This questionnaire contains a set of 23 self-report items assessing three categories of disorders including anorexia nervosa (AN), bulimia nervosa (BN), and binge-eating disorder (BED). Computer coding was used for scoring the questionnaire. Age of the participants was calculated based on the date of birth. Height, and weight were measured according to the standardized protocols [21] using the calibrated instruments (Stadiometer SECA model 213, SECA Corp., Hamburg, Germany, 2008) and (Beurer scale, model GS 202, Beurer GmbH., Germany, 2015), respectively. BMI was calculated as weight $(\mathrm{kg})$ divided by the square of height $\left(\mathrm{m}^{2}\right)$. WC; the distance around the narrowest area of the waist between the lowest rib and iliac crest at the end of a gentle expiration; was measured using a measuring tape. The age- and sex-specific BMI cut-off points were used, provided by the Centre for Disease
Control and Prevention (CDC) according to which the BMI between 85th and 95th percentiles was classified as overweight and BMI above than 95th percentile was considered as obese [22]. AM was recorded for all the participants and their mothers.

\section{Statistical analysis}

Results were expressed as mean \pm standard deviation (SD) for continuous variables and frequencies (\%) for categorical ones. Data normality was checked using Kolmogorov-Smirnov test. The association between $\mathrm{AM}$ and anthropometric parameters was assessed using linear regression. Analyses of Variance (ANOVA) and Tukey's post hoc were used to compare the mean \pm SD of anthropometric parameters between AM groups as well as ED's subgroups. The distribution of socioeconomic characteristics in EDs subgroups was determined by the chi-square test. SPSS software (The Statistical Package for the Social Science, version 23.0, IBM Corp., US, 2016) was used for all statistical analyses, and $p$ value $<0.05$ was considered as statistically significant.

\section{Results}

Mean age was $15.83 \pm 0.99$ years and $75.7 \%$ of the students were 15 years old. Mean of AM in girls was $12.95 \pm 1.14$ years $(n=724)$. After the classification of participants into three groups based on the AM: (1) $12<\mathrm{AM} \leq 14$, (2) $14<\mathrm{AM} \leq 16$ and (3) $9 \leq \mathrm{AM} \leq 12$, the mean of weight, $\mathrm{WC}$, and $\mathrm{BMI}$ in group one were significantly higher than group three (Table 1), however there was no difference in the mean of height between three groups. To recognize the factors associated with AM, linear regression analysis was performed (Table 2). Results showed that there was an inverse significant relationship between weight, BMI, and AM. Menstruation seemed to occur earlier in girls with higher weight or BMI $(p<0.05$, $131 \mathrm{r}=0.1)$. This trend was shown in Additional file 2: Fig. S1A. The data indicated that AM was not significantly related to height and WC. Although, AM had a statistically significant positive correlation with SES, as with increment in the level of SES, AM increased $(p<0.05)$ (Additional file 2: Fig. S1B). We found that there was a statically significant relationship between the AM for girls and their mothers, as 1-month increase in maternal AM caused 4 months delaying of girl's AM $(r=0.34$, $p<0.001)$. Distribution of EDs among all participants was as follow: AN: $11.7 \%(n=85), B N: 5.2 \%(n=38)$, and BED: $0.7 \%(n=5)$. Because of the low prevalence of BED, we supposed BED and BN subgroups as one group. Table 3 illustrates the mean values and SD of AM and anthropometric measurements in control and EDs groups. Analysis showed positive and inverse significant relationships of weight, BMI, WC with BN \& BEDs and 
Table 1 Mean (SD) of basic characteristics in girls based on groups of $A M\left(n=724^{\mathrm{a}}\right)$

\begin{tabular}{|c|c|c|c|c|}
\hline Variables & $\begin{array}{l}1 \\
9 \leq A M \leq 12 \\
n=232\end{array}$ & $\begin{array}{l}2 \\
12<A M \leq 14 \\
n=437\end{array}$ & $\begin{array}{l}3 \\
14<A M \leq 16 \\
n=55\end{array}$ & Total \\
\hline Height (cm) & $160.40(5.83)$ & $160.81(5.58)$ & $161.02(4.94)$ & $160.69(5.61)$ \\
\hline Weight (kg) & $60.03(10.72)^{b}$ & $57.21(10.66)^{b}$ & $56.66(13.39)$ & $58.06(10.98)$ \\
\hline Waist circumference (cm) & $74.12(8.27)^{c}$ & $72.51(7.87)^{c}$ & $73.08(8.43)$ & $73.07(8.06)$ \\
\hline Body mass index $\left(\mathrm{kg} / \mathrm{m}^{2}\right)$ & $23.32(3.97)^{b, d}$ & $22.09(3.83)^{d}$ & $21.84(4.75)^{b}$ & $22.46(3.99)$ \\
\hline Mothers' AM (years) & $13(1.47)^{d}$ & $13.65(1.07)^{c, d}$ & $14.36(0.99)^{c, d}$ & $13.50(1.27)$ \\
\hline
\end{tabular}

Groups are based on the age at which menstruation was occurred

$A M$ age at menarche

a One person was ignored because of delayed menarche

b $\mathrm{p}<0.01$

c $\mathrm{p}<0.05$

d $\mathrm{p}<0.001$

Table 2 Regression analysis of AM and basic characteristics of girls $(n=724)$

\begin{tabular}{lcc}
\hline Variables & p value & $\boldsymbol{\beta} \mathbf{( 9 5 \% ~ C l )}$ \\
\hline Weight $(\mathrm{kg})$ & $<0.01$ & $-0.01(-0.019,-0.004)$ \\
Height $(\mathrm{cm})$ & 0.2 & $0.01(-0.005,0.025)$ \\
WC $(\mathrm{cm})$ & 0.1 & $-0.009(-0.019,0.002)$ \\
BMI $\left(\mathrm{kg} / \mathrm{m}^{2}\right)$ & $<0.001$ & $-0.03(-0.06,-0.018)$ \\
Mother's AM (year) & $<0.001$ & $0.3(-0.0242,0.381)$ \\
SES & $<0.05$ & $0.1(0.003,0.322)$
\end{tabular}

$A M$ age at menarche, $W C$ waist circumference, $B M I$ body mass index; SES: socioeconomic status, $\mathrm{Cl}$ confidence interval

Linear regression was performed; $p<0.05$

Table 3 Mean (SD) of AM and anthropometric measurements in control and eating disorder groups

\begin{tabular}{lccc}
\hline Variables & CONT $(\mathbf{n = 5 9 7 )}$ & ED $(\mathbf{n}=\mathbf{1 2 8})$ & \\
\cline { 3 - 4 } & & AN $(\mathbf{n}=\mathbf{8 5})$ & BN \& BED $(\mathbf{n = 3 8})$ \\
\hline AM (years) & $12.91(1.1)$ & $13.20(1.07)$ & $13.04(1.1)^{*}$ \\
BMl (kg/m²) & $23.02(3.6)$ & $17.48(1.5)$ & $24.64(4.5)^{* *}$ \\
Weight (kg) & $59.48(10.1)$ & $45.11(5.3)$ & $64.20(12.2)^{* *}$ \\
Height (cm) & $160.68(5.6)$ & $160.48(5.03)$ & $161.34(5.7)^{* * *}$ \\
WC (cm) & $73.95(7.6)$ & $65.20(4.7)$ & $76.50(10.1)^{* *}$
\end{tabular}

$A M$ age at menarche, $A N$ anorexia nervosa, $B N \& B E D$ bulimia nervosa \& bingeeating disorder, $B M I$ body mass index, WC waist circumference

Analysis of Variance (ANOVA) was performed; $p<0.05$

* $\mathrm{p}<0.05$

** $p<0.001$

*** Not significant

AN subgroups respectively. No significant relationship was seen between height and EDs groups. A significant correlation was found between AM and EDs as AM was occurred later in EDs subgroups.

Distribution of socioeconomic characteristics in EDs subgroups has been shown in Additional file 1: Table S1. As shown in the Table, there was a significant relationship between normal and EDs groups as regards father's income category $(p=0.03)$. Most of the participants' fathers had middle income. The relationship between normal and EDs groups with regards mother's education was also significant $(p=0.01)$. Most of the participants' mothers belonged to "Diploma" and "Elementary and illiterate" subgroups in normal and EDs groups, respectively. SES in the most of the participants was determined as "middle" and with regards to this parameter, the relationship between normal and EDs groups was close to significant $(p=0.05)$.

\section{Discussion}

In the present study, mean $\pm \mathrm{SD}$ of $\mathrm{AM}$ was $12.95 \pm 1.14$ and $13.5 \pm 1.27154$ years for girls and their mothers, respectively. Ghergherechi and Shoari in a study conducted in Tabriz (2011) showed that mean \pm SD of AM was $12.58 \pm 1.30$ and $13.22 \pm 1.22$ years for girls and their mothers, respectively [23]. Results of both studies indicated that mean AM of girls has been decreased compared to that of mothers over the years. Seemingly, this decrease can be explained by changes in lifestyles and increase in overweight and obesity rate between the two generations.

In the present study, AM was inversely correlated with weight and BMI, which was similar to the study by Tehrani et al. [24], who found that overweight girls experienced menarche earlier than obese ones. Several studies [16, 18, 23, 25-27] have also shown that BMI was inversely correlated with AM but Bazrafshan et al. [17], 
found no significant association neither between BMI and AM nor weight and AM.

Our results demonstrated no significant associations between height and AM, which was in line with other studies [3, 16]. Unlike our results, Okasha et al. [28], and Farahmand et al. [18], reported that height had a positive significant correlation with AM. Our results also did not find any relationship between WC and AM but mean WC was higher in group one $(9 \leq \mathrm{AM} \leq 12)$ compared to the others. However, other studies have shown inverse association between WC and AM [16, 18]. These discrepancies could be due to demographic and genetic differences between study populations.

Our results showed a significant positive correlation between AM and SES, which was in contrast to the studies by Mee-Hwa Lee et al. [3], Gharavi et al. [29], and Delvarianzadeh et al. [25], who did not find any significant relationship between SES and AM. Asgharnia et al. [26], showed that subjects in upper socioeconomic class experienced menarche earlier. Krieger et al. [2], indicated that although mean $\mathrm{AM}$ is declining but patterns vary with respect to socioeconomic strata. Since, there are no standard tools for measuring SES; researchers mainly rely on the tools designed by them, which may lead to different results in studies. AM of the mothers is one of the strongest predictors of AM in their daughters. Herein, a positive strong correlation was observed between daughters' and maternal AM, which was in accordance with the findings reported by other studies [23,24,30], suggesting that AM between two generations is partly controlled by genetic pattern [30].

Our results demonstrated significant relationships between weight, BMI, WC, and EDs subgroups so that, weight, $\mathrm{BMI}$, and $\mathrm{WC}$ were lower in $\mathrm{AN}$ group and higher in BN and BED groups. These associations have been also found in earlier studies [31, 32]. In the AN group, having an energy-restricted diet and trying to lose weight were found to result in being underweight and excessive consumption of food and the lack of control on the amount of the consumed food in the BN and BED groups were found to result in being overweight or obese.

No significant relationship was observed between height and EDs subgroups. According to review of the literature, there was no study investigated the effects of EDs on height of the people. Since, this study was a cross-sectional study and height changes are time-dependent, thus prospective studies are needed to understand whether EDs can lead to short stature. Results of the current study revealed that AM occurred later in EDs subgroups, which was in contrast to the studies by Yannakoulia et al. [31], and Almuhlafi et al. [33], who observed that subjects with early menarche had higher scores of ED behaviours. This can be explained by the fact that a decrease in body fat mass may cause menstrual abnormalities and it is believed that discrepancies in results may be due to geographical and demographic differences of the subjects.

The findings of this study indicated an inverse association between father's income, mother's education, and SES with EDs as EDs were found to be lower in 197 subjects with higher father's income, mother's education and SES strata. Yannakoulia et al. [31], did not find any association between socio-demographic characteristics and eating attitudes. As mentioned earlier, it can be due to different definitions of SES in the studies.

\section{Conclusion}

Due to the reduction of AM and its relationship with unfavourable psychopathological health conditions like EDs, determining factors affecting AM, control related risk factors and reproductive health education should be considered as important health system priorities.

\section{Limitations}

The role of pre-existing psychiatric disorders or family history of a psychiatric disorder was not considered in this study, and it was not possible to determine its effects on the results, thus it was regarded as the main limitation of this study.

\section{Supplementary Information}

The online version contains supplementary material available at https://doi. org/10.1186/s13104-021-05482-2.

Additional file 1: Table S1. Distribution of socioeconomic characteristics in Eating Disorders (EDs) subgroups ( $n=725)$.

Additional file 2: Figure S1. (A) Age at menarche (AM) depending on body mass index (BMI). AM had an inverse significant relationship with $\mathrm{BMI}$, as menstruation was occurred earlier in girls with higher BMI. (B) Age at menarche (AM) depending on socio-economic status (SES). AM had a statistically significant positive correlation with SES, as with increment in the level of SES, AM increased.

\section{Abbreviations}

AM: Age onset of menarche; AN: Anorexia nervosa; ANOVA: Analyses of Variance; BED: Binge eating disorders; BMI: Body mass index; BN: Bulimia nervosa; CDC: Center for Disease Control and Prevention; EDDS: Eating Disorder Diagnostic Scale; EDs: Eating disorders; SES: Socioeconomic status; WC: Waist circumference.

\section{Acknowledgements}

The authors are grateful for the financial support of the Nutrition Research Center, Tabriz University of Medical Sciences. The authors also are deeply indebted to all subjects who participated in this study. This article was written based on a dataset of an MSc thesis (Lida Daeie-Farshbaf) registered in Tabriz university of Medical sciences.

\section{Authors' contributions}

Study designation and drafting the manuscript: LD, AT, ME. Data collection: LD, PS. Data analysis: LD. Providing critical comments on the final manuscript: ME, PS, AT and NR. 


\section{Funding}

This work was founded by the Nutrition Research Center, Tabriz University of Medical Sciences.

\section{Availability of data and materials}

The dataset analyzed during the current study is available from the corresponding author on reasonable request.

\section{Ethics approval and consent to participate}

This study was conducted according to the guidelines laid down in the declaration of Helsinki. Parental consent form was delivered to girls $<16$ for filling at home, then returned to researcher. Additionally written informed consent was obtained from all participants themselves. Approval for this trial was granted by the ethical committee of Tabriz University of Medical Sciences (Ethical Code: TBZMED.REC.1394.593).

\section{Consent for publication}

Not applicable.

\section{Competing interests}

The authors declare that they have no competing interests.

\section{Author details}

1 Student Research Committee, School of Nutrition and Food Sciences, Tabriz University of Medical Sciences, Tabriz, Iran. ${ }^{2}$ Nutrition Research Center, School of Nutrition and Food Sciences, Tabriz University of Medical Sciences, Attar Nishabouri St., POBOX: 14711, Tabriz 5166614711, Iran. ${ }^{3}$ Statistic and Epidemiology Research Center, Tabriz University Medical Sciences, Tabriz, Iran. ${ }^{4}$ Cardiovascular Research Center, Tabriz University of Medical Sciences, Tabriz, Iran.

Received: 30 September 2020 Accepted: 10 February 2021

Published online: 25 February 2021

\section{References}

1. Mahan L, Raymond J. Krause's food \& the nutrition care process: nutrition in adolescence. 14th ed. St. Louis: Elsevier Health Sciences; 2017. p. $331-51$.

2. Krieger N, Kian M, Kosheleva A, Waterman P, Chen J, Beckfield J. Age at menarche: 50-year socioeconomic trends among US-born black and white women. Am J Public Health. 2015;105:388-97. https://doi. org/10.2105/AJPH.2014.301936.

3. Lee MH, Kim SH, Oh M, Lee KW, Park MJ. Age at menarche in Korean adolescents: trends and influencing factors. Reprod Health. 2016;13:121. https://doi.org/10.1186/s12978-016-0240-y.

4. Lakshman R, Forouhi NG, Sharp SJ, Luben R, Bingham SA, Khaw KT, et al. Early age at menarche associated with cardiovascular disease and mortality. J Clin Endocrinol Metab. 2009;94:4953-60. https://doi.org/10.1210/ jc.2009-1789.

5. Lakshman R, Forouhi N, Luben R, Bingham S, Khaw K, Wareham N, et al. Association between age at menarche and risk of diabetes in adults: results from the EPIC-Norfolk cohort study. Diabetologia. 2008;51:781-6. https://doi.org/10.1007/s00125-008-0948-5.

6. Graber JA. Pubertal timing and the development of psychopathology in adolescence and beyond. Horm Behav. 2013;64:262-9. https://doi. org/10.1016/j.yhbeh.2013.04.003.

7. Negriff S, Susman EJ. Pubertal timing, depression, and externalizing problems: a framework, review, and examination of gender differences. J Res Adolesc. 2011;21:717-46. https://doi.org/10.1111/j.1532-7795.2010.00708 $x$.

8. Van Wieringen J. Secular growth changes. In: Human growth. Boston: Springer; 1978. p. 445-73.

9. Eveleth PB. Population differences in growth: environmental and genetic factors. In: Human growth. Boston: Springer; 1979. p. 373-94. https://doi. org/10.1007/978-1-4684-0817-1_12.

10. Matkovic V, Ilich JZ, Skugor M, Badenhop NE, Goel P, Clairmont A, et al Leptin is inversely related to age at menarche in human females. Clin Endocrinol Metab. 1997;82:3239-45. https://doi.org/10.1210/ jcem.82.10.4280.
11. Marjorie E, Kaplan S, Vaughn I. Impact of anorexia, bulimia and obesity on the gynecologic health of adolescents. Am Fam Physician. 2001:64:445-51.

12. Golden NH, Carlson JL. The pathophysiology of amenorrhea in the adolescent. Ann N Y Acad Sci. 2008;1135:163-78.

13. Wiksten-almtromer M, Hirschberg AL, Hagenfeldt K. Prospective follow-up of menstrual disorders in adolescence and prognostic factors. Acta Obstet Gynecol Scand Suppl. 2008;87:1162-8. https://doi. org/10.1080/00016340802478166

14. Bralić I, Tahirović H, Matanić D, Vrdoljak O, Stojanović-Špehar S, Kovačić $V$, et al. Association of early menarche age and overweight/obesity. J Pediatr Endocrinol Metab. 2012;25:57-62. https://doi.org/10.1515/ jpem-2011-0277.

15. De Leonibus C, Marcovecchio M, Chiavaroli V, De Giorgis T, Chiarelli F, Mohn A. Timing of puberty and physical growth in obese children: a longitudinal study in boys and girls. Pediatr Obes. 2014;9:292-9. https:// doi.org/10.1111/j.2047-6310.2013.00176.x

16. Gavela-Pérez T, Garcés C, Navarro-Sánchez P, López Villanueva L, SorianoGuillén L. Earlier menarcheal age in S panish girls is related with an increase in body mass index between pre-pubertal school age and adolescence. Pediatr Obes. 2015;10:410-5. https://doi.org/10.1111/ijpo.277.

17. Bazrafshan H, Behnampour N, Sarabandi F, Mirpour S. Association between puberty and weight, height and body mass index in a developing community. J Pak Med Assoc. 2012;62:54.

18. Farahmand M, Tehrani FR, Azizi F. Whether age of menarche is influenced by body mass index and lipoproteins profile? A retrospective study. Iran J Reprod Med. 2012;10:337.

19. Stice E, Telch CF, Rizvi SL. Development and validation of the Eating Disorder Diagnostic Scale: a brief self-report measure of anorexia, bulimia, and binge-eating disorder. Psychol Assess. 2000;12:123. https://doi. org/10.1037/1040-3590.12.2.123.

20. Khabir L, Mohammadi N, Rahimi Ch. Validation of eating disorders diagnosis scale. J Kermanshah Univ Med Sci. 2014;18:100-7.

21. World Health Organization. Measuring obesity_classification and description of anthropometric data. Report on a WHO consultation of the epidemiology of obesity. Warsaw 21-23 October 1987. Copenhagen: WHO, 1989. Nutrition Unit document EUR/ICP/NUT; 1987. p. 123.

22. Ogden CL, Kuczmarski RJ, Flegal K, Mei Z, Guo S, Wei R, et al. Centers for disease control and prevention 2000 growth charts for the United States: improvements to the 1977 National Center for Health Statistics version. Pediatrics. 2002;109:45-60.

23. Ghergherehchi R, Shoaree N. Age of puberty and its relationship with body mass index in Iranian girls living in Tabriz. Med J Tabriz Univ Med Sci. 2011;33:63-8.

24. Tehrani F, Mirmiran P, Zahedi Asl S, Nakhoda K, Azizi F. Menarcheal age of mothers and daughters: Tehran lipid and glucose study. East Mediterr Health J. 2010;16:391-5.

25. Delvarian-Zadeh M, Khosravi A, Bolbolhaghighi N, Ebrahimi H. Relationship between anthropometric parameters with menarche age of school girls (11-14 years old) in Shahroud. Knowl Health. 2008;3:43-7.

26. Asgharnia M, Faraji R, Sharami H, Yadak M, Oudi M. A study of menarcheal age in Northern Iran (Rasht). Oman Med J. 2009;24:95. https://doi. org/10.5001/omj.2009.22.

27. Ahn JH, Lim SW, Song BS, Seo J, Lee JA, Kim DH, et al. Age at menarche in the Korean female: secular trends and relationship to adulthood body mass index. Ann Pediatr Endocrinol Metab. 2013;18:60. https://doi. org/10.6065/apem.2013.18.2.60.

28. Okasha M, McCarron P, Smith GD, McEwen J. Age at menarche: secular trends and association with adult anthropometric measures. Ann Hum Biol. 2001;28:68-78. https://doi.org/10.1080/03014460150201896.

29. Gharravi AM, Gharravi S, Marjani A, Moradi A, Golalipour MJ. Correlation of age at menarche and height in Iranian student girls living in GorganNortheast of Iran. J Pak Med Assoc. 2008;58:426-9.

30. Morris DH, Jones ME, Schoemaker MJ, Ashworth A, Swerdlow AJ. Familial concordance for age at menarche: analyses from the Breakthrough Generations Study. Paediatr Perinat Epidemiol. 2011;25:306-11. https:// doi.org/10.1111/j.1365-3016.2010.01183.x.

31. Yannakoulia M, Matalas AL, Yiannakouris N, Papoutsakis C, Passos M, Klimis-Zacas D. Disordered eating attitudes: an emerging health problem among Mediterranean adolescents. Eat Weight Disord Stud Anorex Bulim Obes. 2004;9:126-33. https://doi.org/10.1007/BF03325056. 
32. Micali N, Solmi F, Horton NJ, Crosby RD, Eddy KT, Calzo JP, et al. Adolescent eating disorders predict psychiatric, high-risk behaviors and weight outcomes in young adulthood. J Am Acad Child Adolesc Psychiatry. 2015;54:652-9. https://doi.org/10.1016/j.jaac.2015.05.009.

33. Almuhlafi M, Jamilah KA, Almutairi AF, Salam M. Relationship between early menarche, obesity, and disordered eating behaviors: a school-based cross-sectional survey in Northern Saudi Arabia. Diabetes Metab Syndr Obes. 2018;11:743. https://doi.org/10.2147/DMSO.S180697.

\section{Publisher's Note}

Springer Nature remains neutral with regard to jurisdictional claims in published maps and institutional affiliations.
Ready to submit your research? Choose BMC and benefit from:

- fast, convenient online submission

- thorough peer review by experienced researchers in your field

- rapid publication on acceptance

- support for research data, including large and complex data types

- gold Open Access which fosters wider collaboration and increased citations

- maximum visibility for your research: over $100 \mathrm{M}$ website views per year

At BMC, research is always in progress.

Learn more biomedcentral.com/submissions 